\title{
FROM GREENER TIMES: A NEW SPECIES OF THICK-THUMBED MYOTIS FROM PHNOM PENH, CAMBODIA
}

\author{
GÁbor Csorba ${ }^{1, *}$ and NeIL M. Furey ${ }^{2,3}$ \\ ${ }^{1}$ Department of Zoology, Hungarian Natural History Museum \\ H-1088 Budapest, Baross u. 13, Hungary \\ E-mail: csorba.gabor@nhmus.hu; https://orcid.org/0000-0001-5720-4600; corresponding author \\ ${ }^{2}$ Harrison Institute, Bowerwood House, No. 15, St Botolph's Road, Sevenoaks, Kent, TN13 3AQ, UK \\ ${ }^{3}$ Fauna E Flora International, Cambodia Programme \\ No. 19, Street 360, Boeng Keng Kang 1, Chamkarmorn, Phnom Penh, Cambodia, 12302 \\ E-mail: neil.m.furey@gmail.com; https://orcid.org/0000-0003-0439-2446
}

A new species of Myotis is described from Cambodia. The species is characterized by its fleshy, bicoloured thumb, large foot sole, full dentition, relatively short rostrum, and high frontal part of the skull. The species is currently only known from the city of Phnom Penh.

Keywords: Chiroptera, Cambodia, taxonomy, new species, Myotis sp. n.

\section{INTRODUCTION}

Variously developed pads on the thumbs and hind feet can be found in several Southeast Asian vespertilionid genera including Tylonycteris, Glischropus, the monospecific Eudiscopus and one species of Hesperoptenus. A single species of Myotis in the region also has a thickened thumb and a broad, smooth sole on its hind feet. The thick-thumbed Myotis M. rosseti (Oey, 1951) was described from Cambodia and has been placed in different genera by several authors due to its unusual characteristics. In view of its fleshy, wrinkled thumbs and the broad, concave pads on the soles of its hind feet, Oey (1951) originally placed rosseti within Glischropus. Recognizing that the arrangement of its upper incisors, skull shape and several other features challenged this affiliation however, Hill (1969) transferred rosseti to Pipistrellus and regarded it as closely related to Pipistrellus ridleyi, despite the lack of pads on the thumbs or feet of this taxon. Following detailed dental comparisons between Pipistrellus and Myotis, Hill and Topál (1973) reconsidered the generic affinities of rosseti and ridleyi and placed both taxa in the latter genus, where they have subsequently remained.

In February 2000, a single small Myotis was caught in the garden of a private residence in Phnom Penh (the capital of Cambodia) and later deposited in the Hungarian Natural History Museum. This specimen has distinct, lightcoloured and fleshy thumbs and soles on its hind feet, but unlike M. rosset $i$ 
and M. ridleyi, it is a typical Myotis in terms of its dentition, with three upper and lower premolars. Because its external traits, skull shape and unique combination of dental characters collectively differ from any other Myotis of its size within the Indomalayan Region, this specimen is considered distinct and therefore described herein as a new species.

\section{MATERIAL AND METHODS}

Measurements - External measurements were either compiled from the literature or taken from dry skins and alcohol-preserved museum specimens to the nearest $0.1 \mathrm{~mm}$. Craniodental measurements were taken to the nearest $0.01 \mathrm{~mm}$ using digital callipers under a stereo-microscope. Measurements herein include only those taken from non-juveniles, as indicated by the presence of fully ossified metacarpal-phalangeal joints. Definitions of external measurements are as follows: FA: forearm length - from the extremity of the elbow to the extremity of the carpus with the wings folded; TAIL: tail length - from the tip of the tail to its base adjacent to the anus; HF: hind foot - from the tip of the longest digit, excluding the claw, to the extremity of the heel, behind the os calcis; TIB: tibia length - from the knee joint to the ankle; EAR: ear length - from the lower border of the external auditory meatus where it joins with the body to the tip of the pinna; TRAGUS: tragus length - from the lower posterior emargination to the tip of the tragus.

Definitions for craniodental measurements are as follows: GTL: greatest length of skull - greatest antero-posterior diameter of the skull, taken from the most projecting point at each extremity along the median line of the skull, including the incisors; CCL: condylocanine length - from the front of upper canine to the exoccipital condyle; CCW: upper canine width - taken across the outer borders of upper canines; $\mathrm{M}^{3} \mathrm{M}^{3} \mathrm{~W}$ : upper molar width - taken across the outer crowns of the last upper molars; ZYW: zygomatic width - the greatest width of the skull across the zygomatic arches; MAW: mastoid width - the greatest distance across the mastoid region; IOW: interorbital width - the least width of the interorbital constriction; BCW: greatest braincase width - greatest width of the braincase; $\mathrm{BCH}$ : braincase height - taken from the basisphenoid at the level of the hamular processes to the highest part of the skull, including the sagittal crest (where present); $\mathrm{CP}^{4} \mathrm{~L}$ : upper canine-premolar length - from the front of upper canine to the back of the crown of the last premolar; $\mathrm{CM}^{3} \mathrm{~L}$ : maxillary toothrow length - from the front of upper canine to the back of the crown of the third molar; ML: length of mandible - from the anterior rim of the alveolus of the first lower incisor to the most posterior part of the condyle; $\mathrm{CM}_{3} \mathrm{~L}$ : mandibular toothrow length - from the front of the lower canine to the back of the crown of the third lower molar; $\mathrm{CPH}$ : least height of the coronoid process - from the tip of the coronoid process to the apex of the indentation on the inferior surface of the ramus adjacent to the angular process. Absolute height was used in all comparisons of height between individual teeth. Height comparisons of hypoconids relative to entoconids were standardized by ensuring the ramus of the mandible overlapped in the lateral view in each instance.

Multivariate statistics - To assess the variation in quantitative characters between species, a Principal Component Analysis (PCA) on a correlation matrix including the GTL, $\mathrm{CCL}, \mathrm{CCW}, \mathrm{M}^{3} \mathrm{M}^{3} \mathrm{~W}$, IOW, MAW, BCW, BCH, $\mathrm{CM}^{3} \mathrm{~L}, \mathrm{CP}^{4} \mathrm{~L}$, MANL, $\mathrm{CM}_{3} \mathrm{~L}$ and $\mathrm{CPH}$ measurements was performed in R 4.1.1 (R Core Team 2021) using the Rcmdr 2.7-1 (Fox 2017) and FactoMineR 2.4 (Lê et al. 2008) packages. 
Comparative material - The following comparative material was used:

Myotis alticraniatus: Laos - MHNG 1956.089-093; Vietnam - HNHM 88.51.1., 93.56.1., IEBR 1937, 1939, NH45, NH60, NTS1661, XN104, XN13, USNM 260612 (holotype), FMNH 32173, 32175, 32178 (paratypes).

Myotis annamiticus: Vietnam - ZMMU 167134 (paratype).

Myotis ater: Cambodia - CBC00466, СBC00467, СВC00579, СВC00580, СВC00620, CBC00646, СВC01143, СВC01152, СВC01225, СВC01227, СВC01228, СВС01229, СВС01230, CBC01231, СBC01234, СВC01241, HZM 8.34186, 9.34187, 10.34188, 11.34189; Indonesia $\mathrm{BM}(\mathrm{NH})$ 78.2933-2934, ZMB 66981 (syntype); Malaysia - BM(NH) 1999.304-305; Vietnam - HZM 1.30786, 2.31638, 3.31693, 4.31753, 5.32380, IEBR 1486, PL16, PL18, PM027, VC43, VC44, VC47, YD03, YD04.

Myotis davidii: China - MNHN 1987-296 (holotype).

Myotis montivagus: China - BM(NH) 1876.3.10.5 (holotype).

Myotis muricola: Cambodia - CBC02007, HNHM 2005.82.20.-21, HZM 21.33431; Indonesia - BM(NH) 10.4.6.27, 9.1.5.375; Malaysia - HZM 9.3537; Nepal - BM(NH) 45.1.8.143 (holotype), 45.1.8.417, HNHM 99.15.1.; Singapore - HZM 1.1178, 2.1180, 4.1182, 5.1183; Thailand - BM(NH) 70.1478-1479, 79.1410-1412; Vietnam - BM(NH) 26.10.4.22, HZM 13.31690, 15.31692, 17.31748, 18.31749, 19.31750.

Myotis nipalensis: India - BM(NH) 10.1.18.1, 16.7.29.37-41, 16.7.29.90, 23.9.1.12, HNHM 92.107.1.

Myotis phanluongi: Vietnam - ZMMU 175156 (paratype).

Myotis rosseti: Cambodia - CBC02148, CBR-00001800, CBR-00001801, CBR-00002563, CBR-00003342, CBR-00003346, RMNH 19629 (holotype), BM(NH) 68.1194; Thailand $\mathrm{BM}(\mathrm{NH})$ 74.336, HNHM 2869.51.b.1-4.

Myotis ridleyi: Malaysia - BM(NH) 1967.1604, 1982.553, 1983.75, 1984.1983, 1898.3.13.6 (holotype), HNHM 26436, 26443, 26444, 26479.

Myotis siligorensis: India - BM(NH) 087911.21.125 (holotype), HNHM 92.106.2.

Myotis sowerbyi: China - HNHM 2011.13.4., 2011.13.6-8., USNM 238869 (holotype).

The museum acronyms are as follows: $\mathrm{BM}(\mathrm{NH})$ - Natural History Museum, London, UK, formerly British Museum (Natural History); CBC / CBR - Centre for Biodiversity Conservation, Royal University of Phnom Penh, Cambodia; HNHM - Hungarian Natural History Museum, Budapest, Hungary; HZM - Harrison Institute, Sevenoaks, UK, formerly Harrison Zoological Museum; IEBR - Institute of Ecology and Biological Resources, Hanoi, Vietnam; MHNG - Muséum d'histoire naturelle de Genève, Geneva, Switzerland; RMNH - Naturalis, Leiden, Netherlands, formerly Rijksmuseum van Natuurlijke Historie; USNM - Smithsonian National Museum of Natural History, Washington D.C., USA; ZMB - Museum für Naturkunde (formerly Zoological Museum), Berlin, Germany; ZMMU - Zoological Museum of Moscow University, Russia.

\section{RESULTS}

The first two PCA components accounted for $92.1 \%$ of the total variance (Table 1). The first principal component was highly correlated with longitudinal cranial measurements, whereas the second principal component was mainly influenced by the dimensions of the braincase and is interpreted as the shape axis. 
Table 1. Factor loadings of selected craniodental characters obtained from principal component analysis.

\begin{tabular}{|c|c|c|c|}
\hline Character & PC1 & PC2 & PC3 \\
\hline GTL & 0.481632 & 0.238369 & -0.2445 \\
\hline CCL & 0.492608 & -0.25738 & 0.405958 \\
\hline $\mathrm{CCW}$ & 0.167081 & 0.162325 & 0.247792 \\
\hline $\mathrm{M}^{3} \mathrm{M}^{3} \mathrm{~W}$ & 0.245524 & 0.106462 & 0.254712 \\
\hline IOW & 0.079 & 0.113189 & 0.383222 \\
\hline MAW & 0.144462 & 0.461822 & 0.01351 \\
\hline BCW & 0.064181 & 0.365012 & 0.205945 \\
\hline $\mathrm{BCH}$ & 0.053707 & 0.341614 & 0.151246 \\
\hline $\mathrm{CM}^{3} \mathrm{~L}$ & 0.265079 & -0.29628 & 0.098194 \\
\hline $\mathrm{CP}^{4} \mathrm{~L}$ & 0.077886 & 0.011114 & 0.093911 \\
\hline MANL & 0.468651 & -0.0857 & -0.61355 \\
\hline $\mathrm{CM}_{3} \mathrm{~L}$ & 0.289147 & -0.34542 & 0.132793 \\
\hline $\mathrm{CPH}$ & 0.153209 & 0.385778 & -0.1552 \\
\hline Eigenvalue & -3.2218 & 0.1169 & 0.0921 \\
\hline Percentage of variance & 88.9263 & 3.2267 & 2.5412 \\
\hline
\end{tabular}

A bivariate scatterplot of the first two principal components (Fig. 1) using 13 craniodental measurements showed good separation between the Phnom Penh Myotis and all other small Myotis from Southeast Asia apart from M. nipalensis and M. muricola. The overlap with these taxa is due to their overall similarity in cranial and dental measurements; nevertheless, the Phnom Penh
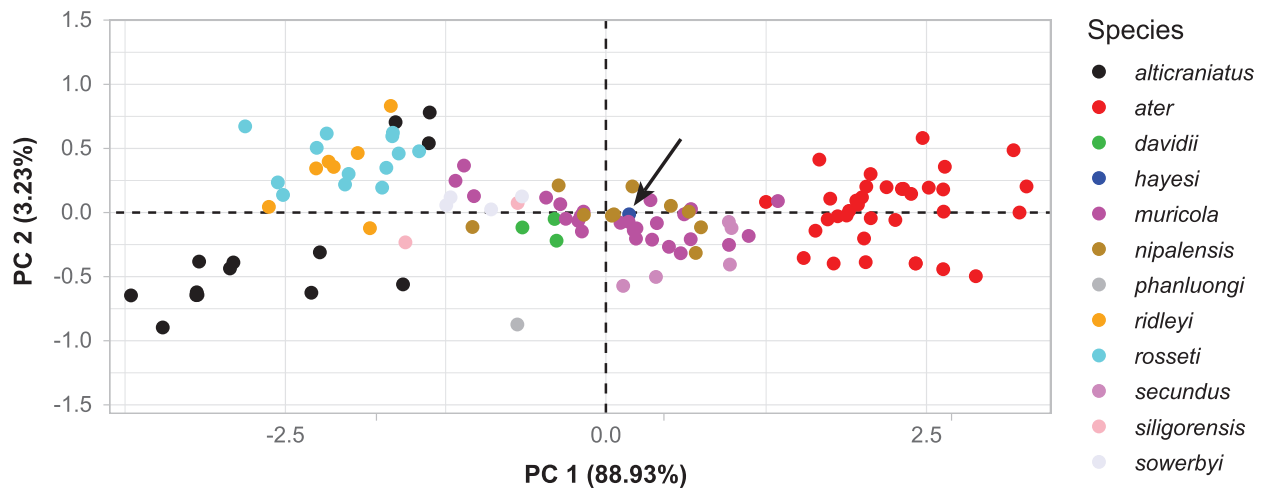

Fig. 1. Principal component analysis of 13 craniodental measurements from 122 adult specimens. Symbols represent the position of an individual skull on the first two principal components 
Myotis can be readily separated from these two species by multiple qualitative morphological traits, as detailed in the comparisons section below.

Overall however, our morphological comparisons indicate that several independent features (i.e. size, skin colour, modifications on the thumbs and hind feet, skull shape, dental characters and baculum morphology) of the Phnom Penh specimen clearly distinguish it from all other species of Southeast Asian Myotis. They also exclude any likelihood of the specimen representing an aberrant individual and support our taxonomic conclusion that it represents a previously undescribed species.

\section{SYSTEMATIC DESCRIPTION}

\section{Myotis hayesi sp. $\mathrm{n}$.}

(Figs 2-7)

Holotype - HNHM 2005.82.32. (field number \# JLW 02.07), adult male, body in alcohol, skull extracted. Collected by Joe L. Walston on 5 February 2000. Measurements for the holotype (in $\mathrm{mm}$ ) are as follows: FA = 33.8; thumb length (excluding claw) $=3.2$; TAIL = 37.1 ; $\mathrm{HF}$ (excluding claws) $=6.5$; longest digit of $\mathrm{HF}$ (excluding claw) $=2.2$; greatest width of $\mathrm{HF}$ (at base of digits) = 3.3; $\mathrm{TIB}=15.7 ; \mathrm{EAR}=12.6$; $\mathrm{TRAGUS}=5.3 ; \mathrm{GTL}=13.64 ; \mathrm{CCL}=$ 12.09; $\mathrm{CCW}=3.56 ; \mathrm{M}^{3} \mathrm{M}^{3} \mathrm{~W}=5.56 ; \mathrm{ZYW}=8.41 ; \mathrm{MAW}=7.13 ; \mathrm{IOW}=3.50 ; \mathrm{BCW}=6.53 ; \mathrm{BCH}$ $=4.72 ; \mathrm{CP}^{4} \mathrm{~L}=2.30 ; \mathrm{CM}^{3} \mathrm{~L}=5.09 ; \mathrm{ML}=9.93 ; \mathrm{CM}_{3} \mathrm{~L}=5.45 ; \mathrm{CPH}=2.92$.

Type locality - Phnom Penh, Cambodia, $11^{\circ} 35^{\prime} \mathrm{N} 104^{\circ} 55^{\prime} \mathrm{E}$. The holotype was collected in an urban area with scattered gardens planted with various species of palms and broad-leaved trees.

Etymology - Named after Benjamin Hayes, in recognition of his exceptional contributions to improving understanding and conservation of bats in Vietnam and Cambodia. The proposed English name is 'Hayes' thick-thumbed myotis'.

Diagnosis - A small species of Myotis (Table 2) with the forearm length of $33.8 \mathrm{~mm}$ and a skull length of $13.64 \mathrm{~mm}$. The thumb, footpad, and calcar (including keel) are distinctly yellowish and contrast sharply with the overall brownish wing membranes. The thumb is shortened and thickened (Fig. 2). The sole of the hind foot is wide, smooth, and concave and its greatest width (measured at the base of the digits) exceeds the length of the longest digit (Fig. 3). The rostrum is relatively short, and the frontal part of the skull is elevated, although the braincase is not especially globose (Fig. 4). There are three upper and lower premolars, and the middle premolars are situated within the toothrow (Fig. 5).

Description - This is a small species of Myotis, with a forearm length of $33.8 \mathrm{~mm}$ (Table 2). The description is based on a wet specimen whose colours might have been influenced by preservation in alcohol. On the dorsal surface, individual hairs in the middorsum are 6.8-7.1 mm long and are medium brown for most of their length with a lighter tip, but without any obvious banding. The fur extends marginally onto the base of the uropatagium and hindlimbs. On the ventral surface, individual hairs are 5.8-6.0 $\mathrm{mm}$ long, 


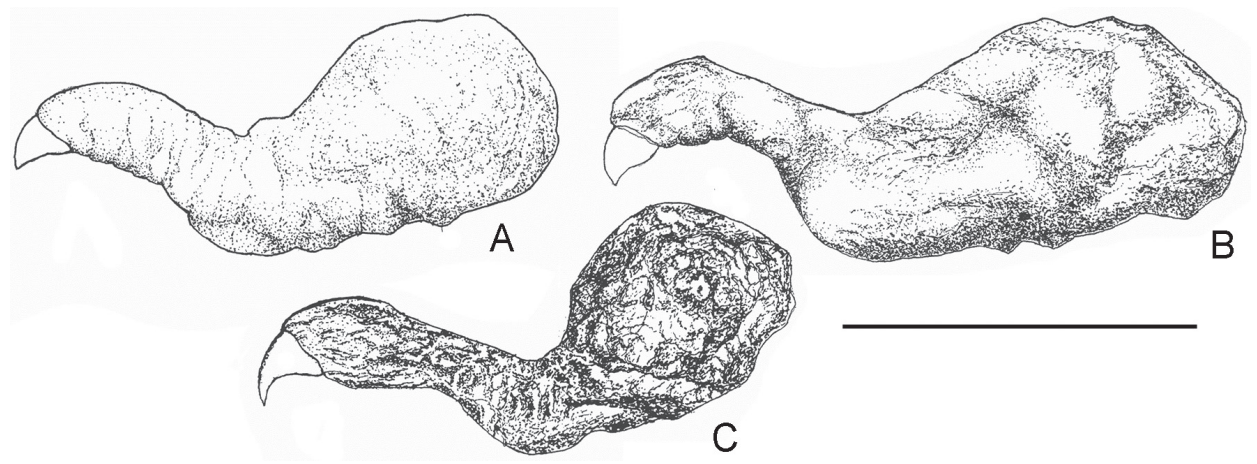

Fig. 2. Right thumb viewed from the leading edge of wing of A) Myotis hayesi sp.n. (holotype, HNHM 2005.82.32.) from Cambodia, B) M. rosseti (HNHM 2869.51.b.1) from Thailand, and C) M. muricola (HNHM 2005.82.20.) from Cambodia. Note the shape of the claw and the relative length of the distal phalanges in relation to the base of the thumb. Scale $=5 \mathrm{~mm}$

medium-brown for approximately $60-70 \%$ of their length and then progressively lighten to pale brown in the remainder. Long hairs which are uniformly of the latter colours occur on and adjacent to the genitalia, whereas thin transverse rows of very short, off-white hairs sparsely occur over much of the uropatagium. The overall impression is of medium brown both above and below.

The nostrils are typical for the genus, as are the ears which are $12.6 \mathrm{~mm}$ in length and just reach the tip of the nose when laid forward. The anterior border of each ear is smoothly convex, and the tip is narrowly rounded and darker in colour than the rest of the yellowish pinna. The distal portion of the posterior margin has a small concavity, whereas the mid-portion is essentially straight. The proximal portion is broadly convex but includes a small flap of skin which renders it strongly convex prior to the base. Short transverse cartilaginous ribs occur on the inner surface of the ear conch. The tragus is narrow for most of its length (1.7 $\mathrm{mm}$ wide near the base), slightly less than half the height of the pinna and
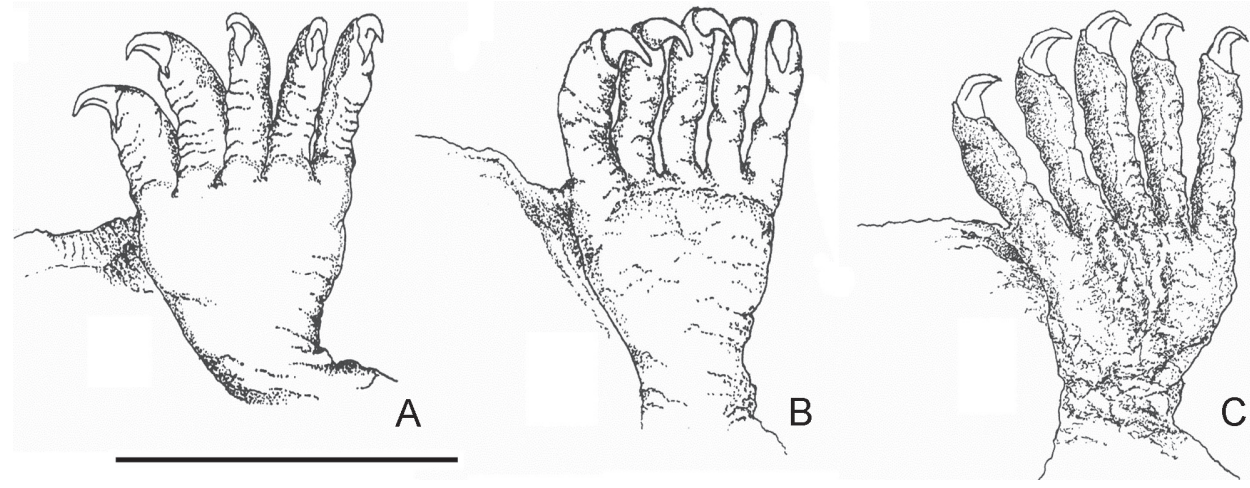

Fig. 3. Plantar view of left hindfoot of $\mathrm{A}=$ Myotis hayesi sp. $\mathrm{n}$. (holotype, HNHM 2005.82.32.) from Cambodia, $\mathrm{B}=\mathrm{M}$. rosseti $(\mathrm{HNHM} 2869.51 . b .2)$ from Thailand, and $\mathrm{C}=$ M. muricola

(HNHM 2005.82.20.) from Cambodia. Scale $=5 \mathrm{~mm}$ 

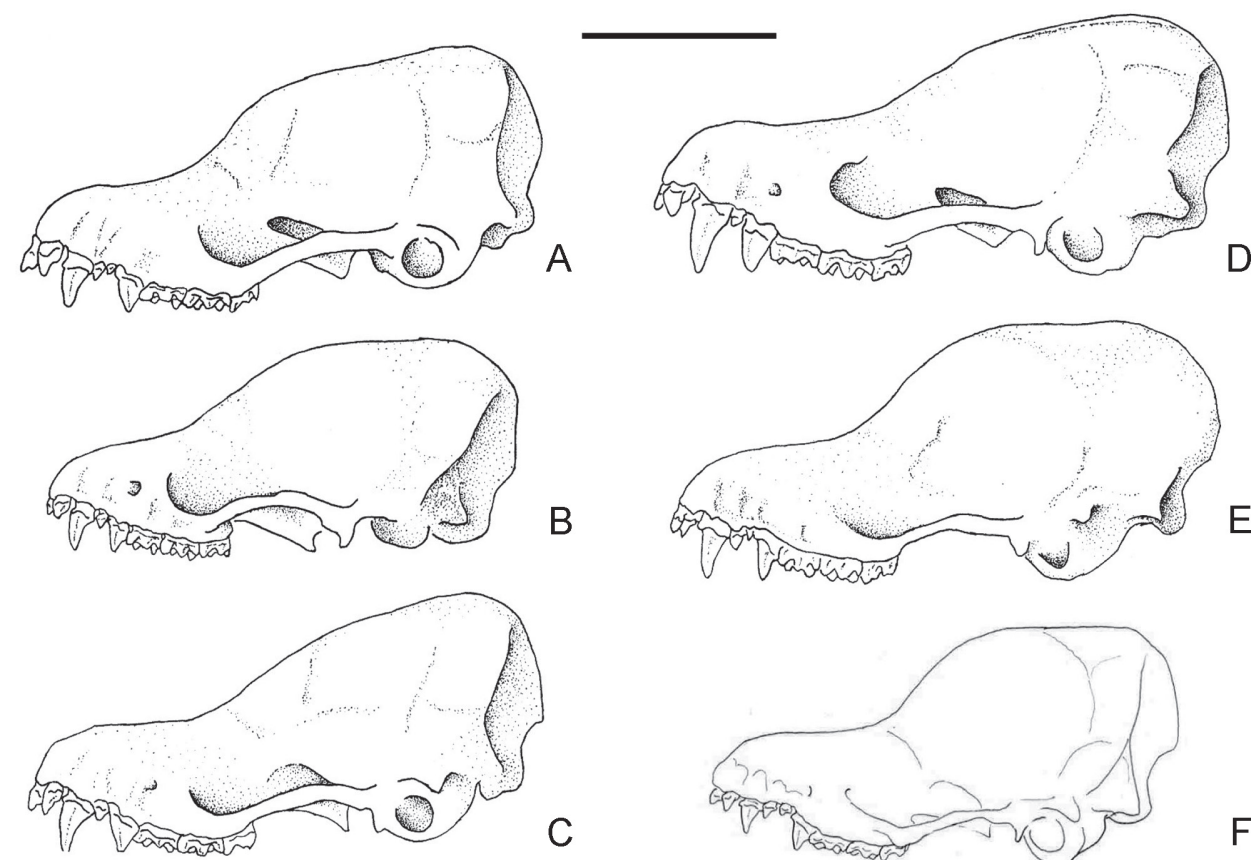

C

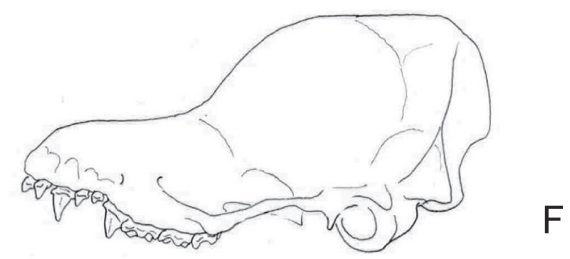

Fig. 4. Lateral view of skulls of Myotis species: $\mathrm{A}=$ M. hayesi sp. n. (holotype, HNHM 2005.82.32.) from Cambodia, $B=M$. rosseti (holotype, RMNH 19629) from Cambodia, $C=$ M. muricola (HNHM 2005.82.20.) from Cambodia, D = M. ater (HZM 10.34188) from Cambodia, $\mathrm{E}=M$. nipalensis $(\mathrm{BM}(\mathrm{NH})$ 16.7.29.38) from West Bengal, India, and $\mathrm{F}=$ M. alticraniatus (MNHG 1956.090) from Lao PDR. Scale $=5 \mathrm{~mm}$

terminates in a pointed tip, which is again darker than the rest of the tragus. Its anterior margin is essentially straight, while the posterior margin is convex and has a small concavity immediately above the base. The face around the eyes is nearly naked, and the skin is light yellowish-brown.

The wings are uniformly brown in colour. The thumb is light brown above and yellowish below and possesses a fleshy pad on its ventral base (Fig. 2). The hind limbs (TIB
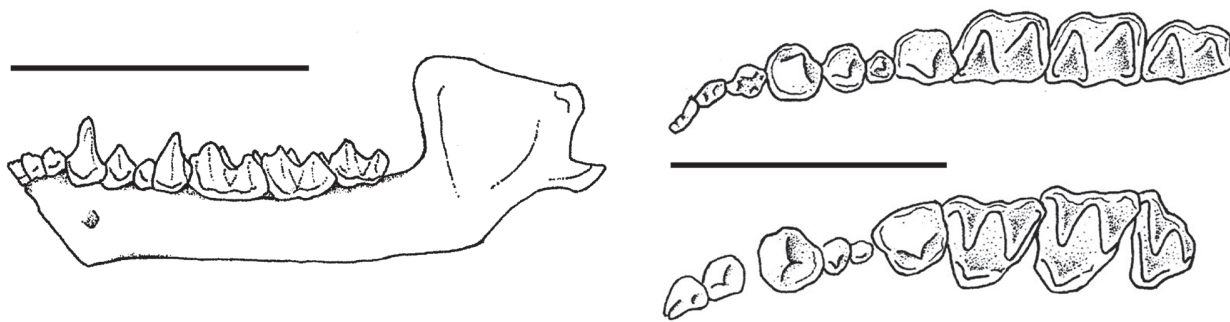

Fig. 5. Lateral view of the mandible (scale $=5 \mathrm{~mm}$ ), and occlusal views of the lower (right) and upper (left) toothrows (scale $=3 \mathrm{~mm}$ ) of Myotis hayesi sp. n. (holotype, HNHM 2005.82.32.) from Cambodia 
$=15.7 \mathrm{~mm})$ and feet $(\mathrm{HF}=6.5 \mathrm{~mm})$ are similarly light brown above and yellowish below. Tail length is $37.1 \mathrm{~mm}$. The calcar has a distinct and elongated keel and is reasonably well developed, occupying approximately half of the trailing edge of the uropatagium. The plagiopatagium is attached to the base of the first toe. The sole of the hind foot is wide, smooth, and concave, and its greatest width $(3.3 \mathrm{~mm})$ exceeds the length of the digits $(2.2$ mm excluding the claws) (Fig. 3).

The penis is light yellowish and ca. $5 \mathrm{~mm}$ long. It slightly widens distally and is generally hairless but possesses scattered, long whitish hairs around the glans.

The skull is small with a greatest skull length (GTL) of $13.64 \mathrm{~mm}$ and a condylocanine length (CCL) of $12.09 \mathrm{~mm}$ (Table 2). In the lateral profile, the anterior portion of the skull ascends relatively steeply and subsequently very gradually, such that the highest point is attained at the rearmost portion of the braincase (Fig. 4). There is no sagittal crest, but the lambdoid crests, although weak, are distinct. The rostrum is relatively short and is not inflated. The posterior border of the palatal emargination extends to the middle of the upper canine. The zygoma are moderately developed and widest posteriorly.

Upper toothrow length $\left(\mathrm{CM}^{3} \mathrm{~L}\right)$ is $5.09 \mathrm{~mm}$ (Table 2). The first upper incisor $\left(\mathrm{I}^{2}\right)$ is bicuspid, with no sign of a third, cingular cusp. Its posterior external face is in contact with the anterior internal face of the second incisor $\left(\mathrm{I}^{3}\right)$, such that $\mathrm{I}^{2}$ is situated anterior to $\mathrm{I}^{3}$ and clearly visible in the lateral view (Fig. 5). $\mathrm{I}^{2}$ possesses a secondary cusp which is posterior to and lower than the principal cusp. $\mathrm{I}^{3}$ is equal in height to $\mathrm{I}^{2}$, slightly larger in crown area (Figs 4-5) and has a tiny cingular cusp on the labial side. It is separated by a brief diastema from the upper canine $\left(\mathrm{C}^{1}\right)$ which is robust and has a well-defined cingulum. The height of $\mathrm{C}^{1}$ distinctly exceeds that of the posterior premolar $\left(\mathrm{P}^{4}\right)$, while its crown area is approximately three-quarters. Both the first and second premolars $\left(\mathrm{P}^{2}, \mathrm{P}^{3}\right)$ are in the toothrow, and $\mathrm{P}^{3}$ is visible in the lateral view and occupies half of $\mathrm{P}^{2}$ in crown area. A faint anterolingual cusp is present on the third premolar $\left(\mathrm{P}^{4}\right)$. The first and second upper molars possess a faint paraconule and paraloph, a metaloph and a well-separated metaconule.

Lower toothrow length $\left(\mathrm{CM}_{3} \mathrm{~L}\right)$ is $5.45 \mathrm{~mm}$ (Table 2). The lower canine $\left(\mathrm{C}_{1}\right)$ has an anterior cingular cusp and a reduced posterior platform. It exceeds the last lower premolar $\left(\mathrm{P}_{4}\right)$ in height but is slightly smaller in crown area. The middle lower premolar $\left(\mathrm{P}_{3}\right)$ is small and attains no more than half the height and one-third of crown area of the first premolar $\left(\mathrm{P}_{2}\right)$. The lower molars are myotodont. The talonids of the first $\left(\mathrm{M}_{1}\right)$ and second $\left(\mathrm{M}_{2}\right)$ molars are well defined and exceed their respective trigonids in crown area. In the lateral view, the entoconids of both teeth distinctly exceed their respective hypoconids in height. The talonid of the third lower molar $\left(\mathrm{M}_{3}\right)$ is reduced in comparison.
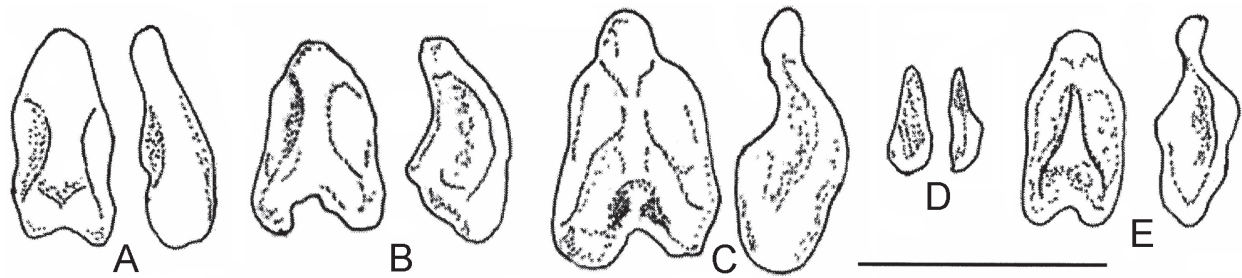

Fig. 6. Bacula (dorsal and right lateral views) of selected Myotis species: $\mathrm{A}=$ M. hayesi sp. $\mathrm{n}$. (holotype, HNHM 2005.82.32.), B = M. annatessae (Vietnam, ZMMU S-164989), C = M. ater (Vietnam, ZMMU S-172604), D = M. alticraniatus (Vietnam, ZMMU S-167188), E = M. muricola (Vietnam, ZMMU S-172616). B-E (D as M. siligorensis) after KRUsкop and Borissenko (2013). Scale bar $=1 \mathrm{~mm}$ 


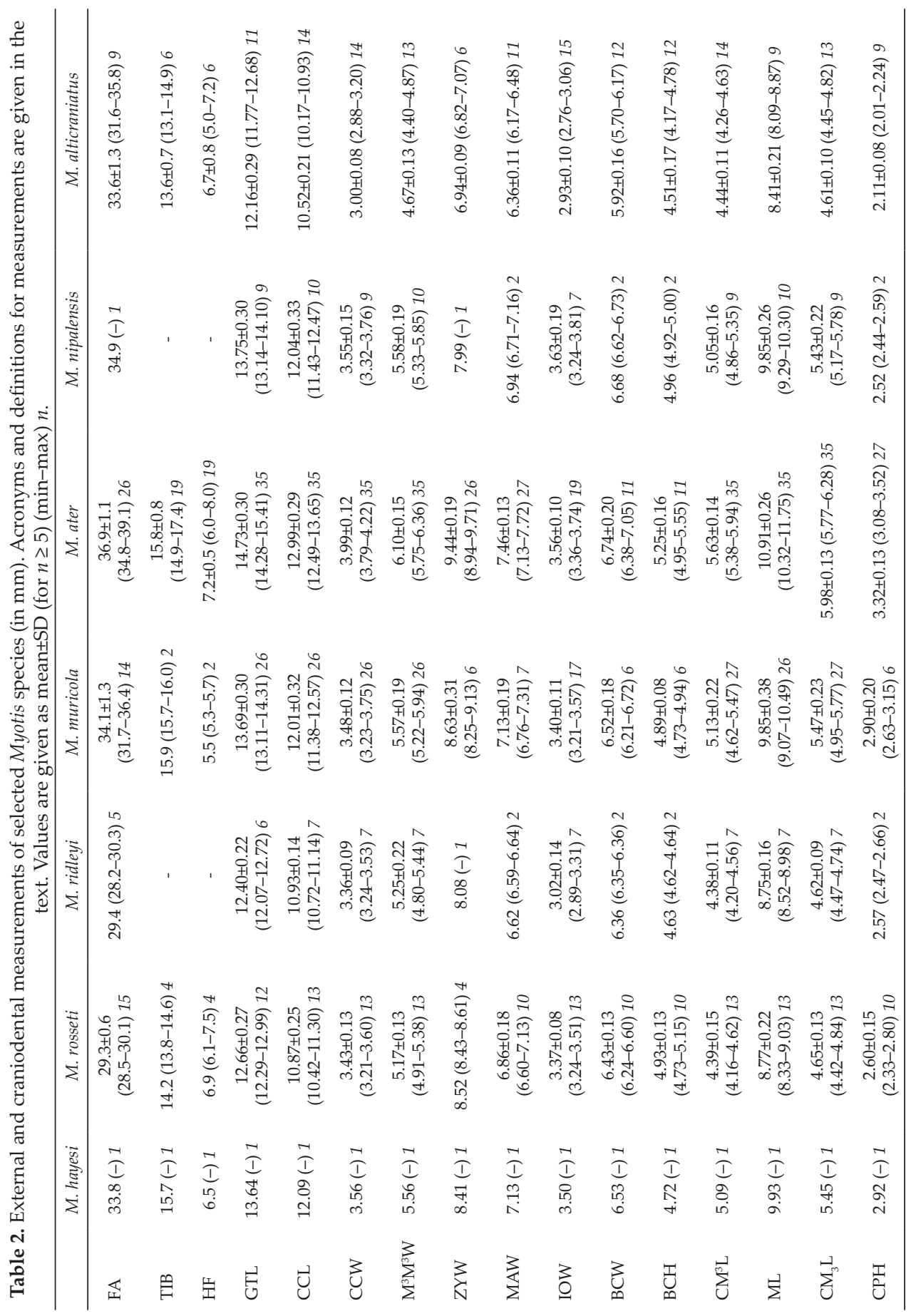


The total length of the baculum is $0.93 \mathrm{~mm}$. Its basal portion is shallowly lobed and in dorsal outline is almost straight sided for the proximal half, then progressively narrows after the mid-point towards a widely rounded tip. The urethral groove is deep. In the lateral view, the distal portion of the baculum is dorsally directed only very slightly and the tip is not curved (Fig. 6).

\section{COMPARISONS WITH OTHER SPECIES}

We employed the findings of RuEDi et al. (2021) and regarded M. annamiticus, M. csorbai and M. badius as potential synonyms of well-established species and organized our taxonomic comparisons accordingly. In light of the revision of the former siligorensis-group by these authors, we also recognize M. sowerbyi as a separate species, albeit one which is morphologically close to M. alticraniatus. As several attempts to extract viable DNA from the alcoholpreserved holotype of $M$. hayesi were regrettably unsuccessful, our comparisons are necessarily confined to morphological features and biometrics.

Myotis hayesi sp. n. differs clearly from all other species of Myotis in the Indomalayan Region in having a short-clawed and thickened thumb (a character shared with $M$. rosseti only: Fig. 2), bicoloured, ventrally yellowish thumbs and hindfeet, plus hindfoot digits which are shorter than the width of the concave sole-pad (Fig. 3). In addition to these differences, M. hayesi is readily distinguished from individual Myotis species in mainland Southeast Asia as follows.

First, all species within the trawling Myotis morphotype, including $M$. fimbriatus, $M$. hasseltii, $M$. horsfieldii, $M$. laniger (including M. annamiticus), $M$. longipes (including M. csorbai) and M. pilosus have distinctly longer hindfeet and plagiopatagia, which are attached higher on the hindlimbs i.e. at or above the middle of the metatarsi.

Second, several taxa within the "Selysius-morphotype" including M. altarium, $M$. annectans, $M$. federatus, $M$. indochinensis, $M$. montivagus and $M$. sicarius are much larger (with a FA over $40 \mathrm{~mm}$ and a $\mathrm{CM}^{3} \mathrm{~L}$ over $5.8 \mathrm{~mm}$ ). Within the same morphotype, several species including $M$. alticraniatus (including $M$. badius), M. phanluongi, M. siligorensis and M. sowerbyi are comparable in size but are readily distinguished from $M$. hayesi by their semi-nyctalodont lower molars. Smaller species within the "Selysius-morphotype" that possess myotodont dentition include $M$. ater, $M$. frater, M. muricola, M. nipalensis, $M$. annatessae, $M$. ancricola, $M$. ridleyi, $M$. rosseti, $M$. secundus and $M$. soror (Table 2). These taxa are morphologically similar to $M$. hayesi but can be individually distinguished as follows.

Myotis ater is differentiated by its dark-brown or blackish fur, longer rostrum, less concave skull profile, larger craniodental measurements (Fig. 4, Table 2), small, lingually displaced middle upper premolar, and much wider baculum with an abruptly narrowing and dorsally-directed tip (Fig. 6). Myotis 
frater and $M$. soror both have a globose frontal part of braincase, strong canines, and lingually-displaced middle upper premolars. Myotis muricola has a longer rostrum, more robust upper canines (Fig. 4), and a baculum with an abruptly narrowing, ventrally-directed and hook-like tip (Fig. 6). Myotis nipalensis and the morphologically similar M. annatessae and M. ancricola are collectively characterized by their white-tipped belly fur (vs. the distally pale-brown ventral fur of $M$. hayesi) and strongly dorsally-directed bacula (although information on the structure of the penial bone is not available for $M$. nipalensis) (Fig. 6). Myotis rosseti and M. ridleyi both have differently shaped skulls with a much shorter rostral portion (Fig. 4), two premolars in the upper and lower toothrows and smaller external, cranial and dental dimensions (Table 2). Myotis secundus is readily separated by its much darker general appearance i.e. dark face, ear and dark brown pelage.

\section{CONSERVATION STATUS}

Little is known about the conservation status of M. hayesi as the species is currently known only from the holotype specimen collected in an area of Phnom Penh with scattered gardens in 2000. The precise location where this individual was encountered is also unclear as the available coordinates (in the degrees, minutes, seconds format) lack the seconds components, although

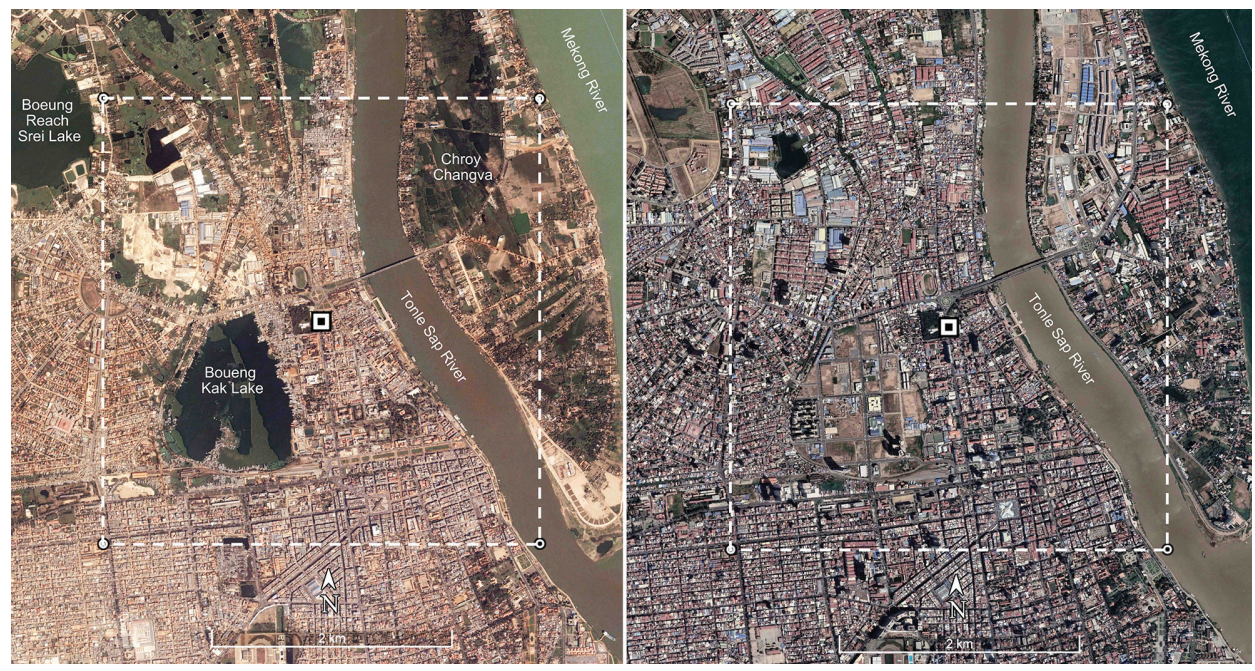

Fig. 7. Landcover in Phnom Penh city in February 2003 (left) and February 2021 (right). The central square symbol represents the available coordinates $\left(11^{\circ} 35^{\prime} \mathrm{N}, 104^{\circ} 55^{\prime} \mathrm{E}\right)$ for the holotype of Myotis hayesi sp. n., whereas the dashed line encloses the area this was likely captured within (NW to SE corner: $11^{\circ} 36^{\prime} \mathrm{N}, 104^{\circ} 54^{\prime} \mathrm{E}$ to $11^{\circ} 34^{\prime} \mathrm{N}, 104^{\circ} 56^{\prime} \mathrm{E}$ ). Imagery from Google-Earth Pro (Google Inc.) 
this was likely within the $13.4 \mathrm{~km}^{2}$ area defined in Figure 7 (which allows for the possibility that the minutes components might have been rounded upwards or downwards when the seconds components were omitted). This, in turn, permits the broader observation that the region of the type locality has lost almost all of its remaining wetlands and green spaces since $M$. hayesi was collected. These include the complete loss of the Boeung Kak Lake and almost all non-urbanized areas in the Chroy Changva area between the Tonle Sap and Mekong rivers, in addition to those formerly present in the north-west quadrant of the type region and adjacent areas, including the Boeung Reach Srei Lake. While little can be said regarding the effects of these developments until more is known about the ecological preferences and wider distribution of $M$. hayesi, these are unlikely to have been advantageous. Notwithstanding this, the species would qualify for listing as Data Deficient on the IUCN Red List given that it is presently known only from a single record despite intensive bat surveys throughout Cambodia over the last decade (e.g., ITH $e t$ al. 2011, Furey et al. 2012, 2016, 2018, ChHeang et al. 2013, Ravon et al. 2013).

*

Acknowledgements - We are indebted to Joe Walston, former Director of the Wildlife Conservation Society (Cambodia Program) for making the specimen available for study. Paula Jenkins, Daphne Hills, Louise Tomsett and Roberto Portela Miquez (The Natural History Museum, London), Vu Dinh Thong, Nguyen Truong Son, Vuong Tan Tu (IEBR), Steven van der Mije, Hein van Grouw and the late Chris Smeenk (Naturalis), Manuel Ruedi (MHNG), Darrin Lunde (USNM), Frieder Mayer (ZMB) and Sergei Kruskop (ZMMU) kindly provided access to the specimens under their care. Anna Honfi elaborated the line drawings, Tamás Görföl and Sándor Zsebők provided expert advice and helped with the multivariate statistics. We are also grateful to Paul Bates, Malcolm Pearch, Karen Bates, and the late David Harrison at the Harrison Institute for their encouragement and help during our visits to Sevenoaks; the two anonymous reviewers provided useful suggestions which were incorporated into the final version. The work of GC received support from the National Research, Development and Innovation Fund of Hungary NKFIH KH130360, and from the SYNTHESYS Project, financed by the European Community Research Infrastructure Action under the FP7 "Capacities" Program. Finally, we would like to thank the Darwin Initiative of the UK Government for their support for taxonomic bat studies in Southeast Asia.

\section{REFERENCES}

Chheang, S., Bates, P. J. J., Boughey, K., Csorba, G., Hayes, B., Ith, S., Mould, A., Phauk, S. \& Furey, N. M. (2013): Further new country records of four bat species (Chiroptera: Mammalia) from Cambodia and a call for information. - Cambodian Journal of Natural History 2013: 73-82.

Fox, J. (2017): Using the R Commander: A point-and-click interface for R. - Chapman and Hall/ CRC Press. 
Furey, N. M., Phauk, S., Phen, S., Chheang, S., Ith, S., Bates, P. J. J. \& Csorba, G. (2012): New country records for five bat species (Chiroptera) from Cambodia. - Cambodian Journal of Natural History 2012: 141-149.

Furey, N. M., Whitten, T., Cappelle, J. \& Racey, P. A. (2016): The conservation status of Cambodian cave bats. Pp. 82-95. In: Laumanns, M. (ed.): International speleological project to Cambodia 2016 (Provinces of Stoeng Treng, Kampong Speu, Banteay Meanchey and Battambang). Berliner Höhlenkundliche Berichte, Vol. 64. - Speläoclub, Berlin.

Furey, N. M., Racey, P. A., Ith, S., Touch, V. \& Cappelle, J. (2018): Reproductive ecology of Chaerephon plicatus (Buchannan, 1800) in relation to guano production in Cambodia. - Diversity 10: 91. https://doi.org/10.3390/d10030091

Hill, J. E. \& Topál, G. (1973): The affinities of Pipistrellus ridleyi Thomas, 1898 and Glischropus rossetti Oey, 1951 (Chiroptera: Vespertilionidae). - Bulletin of the British Museum Natural History (Zoology) 24: 447-454.

Hill, J. E. (1969): The generic status of Glischropus rossetti Oey, 1951 (Chiroptera: Vespertilionidae). - Mammalia 33: 133-139. https://doi.org/10.1515/mamm.1969.33.1.133

Ith, S., Csorba, G., Bates, P. J. J. \& Furey, N. M. (2011): Confirmation of seven bat species for Cambodia. - Cambodian Journal of Natural History 2011: 93-103.

Kruskop, S. V. \& Borissenko, A. V. (2013): A new species of South-East Asian Myotis (Chiroptera: Vespertilionidae), with comments on Vietnamese 'whiskered bats'. - Acta Chiropterologica 15: 293-305. https://doi.org/10.3161/150811013X678937

LÊ, S., Josse, J. \& Husson, F. (2008): FactoMineR: An R package for multivariate analysis. Journal of Statistical Software 25. https://doi.org/10.18637/jss.v025.i01

Oex, H. P. (1951): A new species of bat from Cambodge, Glischropus rossetti sp. nov. Beaufortia 1: 1-6.

Ravon, S., Furey, N. M., Hul, V. \& Cappelle, J. (2014): A rapid assessment of flying fox (Pteropus spp.) colonies in Cambodia. - Cambodian Journal of Natural History 2014: $14-18$.

R Core Team (2021): A language and environment for statistical computing. - R Foundation for Statistical Computing, Vienna, Austria.

Ruedi, M., Saikia, U., Thabah, A., Görföl, T., Thapa, S. \& Csorba, G. (2021): Molecular and morphological revision of small Myotinae from the Himalayas shed new light on the poorly known genus Submyotodon (Chiroptera: Vespertilionidae). - Mammalian Biology 101: 465-480. https://doi.org/10.1007/s42991-020-00081-3

Received June 8, 2021, accepted November 6, 2021, published February 14, 2022 